Annual Research \& Review in Biology
12(3): 1-14, 2017; Article no.ARRB.31526
ISSN: 2347-565X, NLM ID: 101632869
SCIENCEDOMAIN international
WwW.SCiencedomain.org

\title{
Influence of Environmental Factors on Photosynthesis of Three Coniferous Species
}

\author{
Galina Suvorova ${ }^{1}$, Michael Korzukhin ${ }^{2}$ and Maria Ivanova ${ }^{1^{*}}$ \\ ${ }^{1}$ Siberian Institute of Plant Physiology and Biochemistry, Siberian Branch of Russian Academy of \\ Sciences, Irkutsk, Russian Federation. \\ ${ }^{2}$ Institute of Global Climate and Ecology, Moscow, Russian Federation.
}

\begin{abstract}
Authors' contributions
This work was carried out in collaboration between all authors. Author GS designed the study, performed the statistical analysis, wrote the protocol and wrote the first draft of the manuscript. Authors MK and MI managed the analyses of the study. Author MI managed the literature searches.
\end{abstract} All authors read and approved the final manuscript.

Article Information

DOI: $10.9734 / A R R B / 2017 / 31526$

Editor(s):

(1) George Perry, Dean and Professor of Biology, University of Texas at San Antonio, USA.

Reviewers:

(1) Fernanda Ventorim Pacheco, Federal University of Lavras- UFLA, Brazil. (2) Ricardo Antonio Marenco, Instituto Nacional de Pesquisas da Amazônia (INPA), Manaus, Amazonas, Brazil.

(3) Chiachung Chen, National ChungHsing University, Taiwan. (4) Usha Damodhar, Pondicherry Central University, Pondicherry, India. Complete Peer review History: http://www.sciencedomain.org/review-history/18773

Original Research Article

Received $11^{\text {th }}$ January 2017 Accepted $21^{\text {st }}$ April 2017 Published 25 ${ }^{\text {th }}$ April 2017

\section{ABSTRACT}

The effect of five ecological factors (incident radiation, air and soil temperature, vapour pressure deficit $(D)$, and soil moisture) on the net $\mathrm{CO}_{2}$ photosynthesis rate was examined for three boreal tree species - Siberian larch (Larix sibirica), Sibirian spruce (Picea obovata), and Scots pine (Pinus sylvestris) from the Baikal lake region, by means of a coupled photosynthesis-stomatal conductance model. The model was parametrized on the data obtained from 5-year long field measurements made on sun needles of three 14-19 year-old trees of each species. Pine had the greatest photosynthesis rate while spruce had the lowest one. There were 9 free model parameters in total fitted on the whole data set that gave the model efficiency $M E=0.46-0.66$. For single years and three intra-year time intervals, parameter fitting was made for three key parameters only: maximum Rubisco activity, $V_{\text {cmax25 }}$, maximum stomatal conductance, $g_{\mathrm{sw}}$, and quantum efficiency of photosynthesis, $\varphi$; this procedure raised fitting quality to $M E=0.61-0.72$. 
Photosynthesis rate varies due to current weather conditions and also due to long-term changes in the plant itself, that is in the parameters that determine the photosynthesis rate. The change of parameter values with time probably takes place due to between- and within-year weather change. Under actual weather conditions in Pre-Baikalia, larch realises $49 \%$, spruce $-30 \%$, and pine $-36 \%$ of their maximum photosynthesis rate ability. Soil moisture significantly affected $V_{\mathrm{cmax} 25}$ for larch and spruce, while for larch it was vapour pressure deficit $(D)$ that most affected the value of $V_{\mathrm{cmax} 25}$. The coefficient of stomatal limitation of photosynthesis, $L_{\mathrm{s}}$, offered by Sharkey, showed that stomatal regulation is maximal for pine, and minimal for larch.

Keywords: Environmental impact on gas exchange; Siberian larch Siberian spruce; Scots pine coupled photosynthesis; stomatal conductance model.

\section{INTRODUCTION}

Investigations of diversity and peculiarities of historical formation of Baikal region vegetation [1, 2,3 ] demonstrated that peculiarities of structure and dynamics of productivity of forest plantations in this territory are determined by cold soils, high insolation level and moisture deficit. Under these conditions, coniferous species dominate in multyspecies stands due to flexibility of their physiology. So, it seems important to analyze the photosynthetic activity of these plants under natural conditions, and their species-specific dependence on environmental factors.

It is customary to conduct analysis and extrapolation of corresponding empirical data by employing mathematical models that rely on physiological-biochemical mechanisms of photosynthesis, and, as a result, have considerable predictive power. During the last 20-25 years, it was the Farquhar biochemical model [4] that was mostly used for this purpose [for recent examples see 5,6,7,8], sometimes combined with some model of somatal conductance typically, the models of $[9,10]$. Our approach follows this practice.

A large body of studies is devoted to determining the Farquhar model parameters. Most of them examine two central ones: $V_{\mathrm{cmax} 25}$, the maximum carboxylation capacity, and $J_{\max 25}$, the maximum electron transport capacity. Typically, $V_{\text {cmax } 25}$ and $J_{\text {max25 }}$ are determined by processing the $A-C_{\mathrm{i}}$ curves obtained under laboratory conditions. Thus, a summary reported by [11] provides the data on the value of $V_{\text {cmax25 }}$ for 109 plant species (with six tree boreal species among them). Later studies examined the temperature dependence of some components of the model $[12,13]$.

In the original version of the Farquhar model, the external ecological factors are represented by PAR, air temperature, and ambient $\mathrm{CO}_{2}$ concentration. Subsequently soil temperature was incorporated [14], as well as leaf water regime via water potential of soil and plant [15].

However, the use of Farquhar model is complicated by the systematic parameter change due to continual long-term influence of environmental factors leading to adaptive change; for example, this effect was reported for average PAR intensity [16] and for air temperature $[12,17]$. The problem was outlined in detailes in the review by [18].

The goal of this paper is to examine the adaptive differences in dependence of photosynthetic activity on several climatic factors for three dominant coniferous species growing in the sharply continental climate of East Siberia. Our analysis was based on systematic measurements of their $\mathrm{CO}_{2}$ exchange spanning a time interval of five years. The study years differed drastically as regards the weather. The data were published previously, but treated from a different standpoint [19].

In selecting the values of the parameters suitable for model application, special attention was given to the variation of the parameters from year to year and within a growing season.

For the most ecophysiological models, it is rare for the influence of the water and temperature regime of the soil to be taken into consideration, but we had these factors measured together with the photosynthesis rate. Correspondingly, the ecophysiology of selected conifers was studied as to its dependence on five environmental factors: the PAR intensity, air and soil temperatures, vapor pressure deficit in the air, and the available soil moisture. The last factor is especially important because the specimens studied grow in the near-taiga zone with the limits of precipitation in the course of the growing season. 


\section{MATERIALS AND METHODS}

The objects of investigation were represented by Scots pine (Pinus sylvestris L.), Siberian spruce (Picea obovata Ledeb.), and Siberian larch (Larix sibirica Ledeb). These species occur throughout Siberia, from the tundra line to the forest-steppe area. Their ecological traits can be found for example in [20,21]. Pine and larch are durable edificatory and sub-edificatory species in Siberia's coniferous forests. According to a characteristic given by forest ecologists, pine endures moisture deficiency as well as overmoistening, but it does not grow in Siberia on boggy lands because of its root system's sensitivity to the low temperatures of marshy soils. The proportion of spruce in Siberia's forests, especially in East Siberia, is lower when compared with pine and larch (only $7 \%$ of coniferous forests territory of Irkutsk region instead of $34 \%$ for pine and $40 \%$ for larch forests) [22] since it is more soil moisture demanding (it likes neither dry nor water-logged soils), grows in river valleys, occupies mounds and micro-elevations on bogs and is hardly ever found on dry sand soils. It has a poorly developed root system tending toward the surface in comparison with pine and larch ones and is less resistant to the effects of a dry continental climate and high temperatures either.

The measurements were made from 1995 to 1999 on the plantation established in 1984 on the outskirts of the city of Irkutsk, belonging to Siberian Institute of Plant Physiology and Biochemistry SB RAS $\left(52^{\circ} 14^{\prime} \mathrm{N}, 104^{\circ} 16^{\prime} \mathrm{E}\right)$. In September 1999, the plantation had tree species composition PS4SS3LS3 and with the canopy closure being $50-60 \%$. The mean tree size was as follows:

$\begin{array}{llll} & \text { Larch } & \text { Spruce } & \text { Pine } \\ \text { Height, } \mathrm{m} & 5.13 & 3.95 & 4.45 \\ \text { Diameter at a height } & 68.7 & 50.4 & 43.2 \\ \text { of } 1.5 \mathrm{~m}, \mathrm{~mm} & & & \end{array}$

The plantation lies on grey loamy non-podzolic forest soils with a poorly pronounced humus horizon. According to the observations made by [23] the soils within a $0-50 \mathrm{~cm}$ layer may contain in springtime $144 \mathrm{~mm}$ of moisture, with the water content at wilting point of $38 \mathrm{~mm}$. The moisture available for the plants was measured as difference between common water content and content at wilting point: $144-38=106 \mathrm{~mm}$.

In winter the soil freezes to a considerable depth (sometimes up to $200 \mathrm{sm}$ ), and thaws occurs late. Groundwater is at a great depth (11-55 m) and has no influence on the water regime of the upper soil horizons. Tree roots do not penetrate deeper than $100 \mathrm{~cm}$, and the bulk of sucking roots are concentrated in the upper $10 \mathrm{~cm}$ of the soil.

$\mathrm{CO}_{2}$ exchange measurements started in early spring (first-second decade of April) when the first signs of positive (net) $\mathrm{CO}_{2}$ exchange appeared, and were ceased in the first decade of November when the $\mathrm{CO}_{2}$ exchange terminated. Three trees of each species were taken. Non shaded one (last) year old shoots of pine and spruce were selected. Likewise brachyblasts of larch growing on one-year-old shoots on the southern side in the upper third of the crown were selected. To measure the $\mathrm{CO}_{2}$ gas exchange of the needles we used cylindrical polyethylene cuvettes.

Photosynthesis was recorded by means of infrared gas analyzer Infralyt-4 (Germany)-based 12-channel device of open type on the EPP-09 (Russia) recorder with the least division of 5 ppm. The effectiveness of the device was supported by special methodical examination [24]. Volumes of the assimilation cuvettes were adapted to shoot sizes, and were equal to 0.5 $\mathrm{dm}^{3}$ for larch and pine, and $0.2 \mathrm{dm}^{3}$ for spruce. Free polyethylene ends of assimilation cuvettes were fixed on branches by the scotch tape. The air entered the cuvette with air inlet, went around the needles, went to the $\mathrm{CO}_{2}$ measuring device for the analysis and then went out with the exhaust. There were twelve values measured in total: nine values for $\mathrm{CO}_{2}$ exchange, one from each cuvette, and in addition three $\mathrm{CO}_{2}$ concentration measurements were taken in the ambient air near the cuvettes, for control. Switching between the channels was conducted automatically. Air flow was pumped by compressors positioned between channel switches and the air dryer. The ambient $\mathrm{CO}_{2}$ concentration was at the average $330-340 \mathrm{ppm}$ changing about $380 \mathrm{ppm}$ in morning to $320 \mathrm{ppm}$ in afternoon hours.

The rate of air current was $40 \mathrm{I} \mathrm{h}^{-1}$. A calculation of the photosynthesis rate was performed to the projected needle area. Observations were made from 6 to 20 o'clock on 3 consecutive days every week, totalling 12-15 days a month. The length of the period of a positive photosynthesis rate (corresponds to $\mathrm{CO}_{2}$ assimilation) for these 5 years averaged 185 days per year for pine and spruce (from the end of April to the end of 
October), and 137 days per year for larch (from mid-May to 20 of September). Five measurements were made for each object per hour, but for the analysis were used only hourly meanings. A total of 5385 hourly measurements were obtained for pine and spruce, and 4410 measurements for larch with its shorter growing period.

Concurrently with $\mathrm{CO}_{2}$ exchange measurements, we recorded the integral solar irradiation intensity by means of the Yanyshevsky pyranometers. The integral irradiance was converted to photosynthetically active radiation (PAR, $\mu \mathrm{mol}$ $\mathrm{m}^{-2} \mathrm{~s}^{-1}$ ) following [25]. In the middle of the vegetation season in our region this part was around $46-52 \%$. Air temperature was measured with copper temperature-sensitive elements installed in one of the assimilation chambers as well as in the inter-crown space level with the assimilation chambers. Relative air humidity was determined with the hygrograph (Russia), and the readings were compared with the Assman psychrometer (Russia). The data obtained were converted to the values of $D$ by well-known formulas that employ air temperature values. Soil temperature at a depth of $5 \mathrm{~cm}$ was recorded at 1 p.m. every day, and moisture content in the soil was measured once a week by the thermostatweight technique.

The data obtained were analysed by means of application of coupled photosynthesis-stomatal conductance model that is described below.

\subsection{Model Description}

\subsubsection{The submodel of photosynthesis}

The rate of specific net photosynthesis during the daytime per unit leaf area, $A_{n}\left(\mu \mathrm{mol} \mathrm{m} \mathrm{s}^{-1}\right)$ is given by the basic balance equation

$$
A_{\mathrm{n}}\left(Q, T_{\mathrm{a}}, C_{\mathrm{i}}\right)=A_{\mathrm{b}}\left(Q, T_{\mathrm{a}}, C_{\mathrm{i}}\right)-R_{\mathrm{d}}\left(T_{\mathrm{a}}\right),
$$

where $A_{\mathrm{b}}$ is the gross photosynthesis rate, $R_{\mathrm{d}}$ is the daytime dark respiration, $Q$ is PAR intensity, all of the three foregoing being measured in $\mu \mathrm{mol}$ $\mathrm{m}^{-2} \mathrm{~s}^{-1} ; T_{\mathrm{a}},{ }^{0} \mathrm{C}$, is air temperature; $C_{\mathrm{i}}$ is $\mathrm{CO}_{2}$ concentration in the intercellular space.

Gross photosynthesis rate $A_{\mathrm{b}}$ is given by the model of [4] in its original, two limiting processes formulation, where the central parameters are the maximum rate of Rubisco activity, $V_{\mathrm{cmax} 25}$, the potential rate of electron transport, $J_{\max 25}$ (both taken at a reference temperature $T_{\mathrm{a}}=25$ ${ }^{\circ} \mathrm{C}, \mu \mathrm{mol} \mathrm{m} \mathrm{m}^{-2} \mathrm{~s}^{-1}$ ), and the quantum efficiency of photosynthesis, $\varphi$, mol e (mol PAR $)^{-1}$. In our model [26] for full description of our version, one addition was necessary, namely, dependence of assimilation rate on soil temperature, $T_{\mathrm{s}}$. Here we followed the results and formalization reported by $[14,15]$. For three coniferous species from the temperate zone, they found a parabolic-like dependence of $V_{c \max 25}, J_{\max 25}$, and $\varphi$ on $T_{s}$; our parametrisation will be described later.

Photosynthesis rate over a $24-\mathrm{h}$ period is found by substracting from $A_{n}$ the night respiration rate $R_{\mathrm{n}}, \mu \mathrm{mol} \mathrm{m} \mathrm{m}^{-2}$; the last is commonly taken being proportional to $R_{\mathrm{d}}$ :

$$
R_{\mathrm{n}}=r_{\mathrm{nd}} R_{\mathrm{d}}
$$

where the parameter $r_{\text {nd }}$ ranges between 1.25 and 5.0 [27] with a typical value of 2.0 used in our calculations.

Stomatal conductance for $\mathrm{H}_{2} \mathrm{O}$ was calculated using the widely used semi-empirical model of [9]:

$$
\begin{aligned}
& g_{\mathrm{Sw}}\left(Q, T_{\mathrm{a}}, D, T_{\mathrm{s}}, W_{\mathrm{s}}\right)=g_{\mathrm{W}}^{\text {cut }}+\left(g_{\mathrm{SW}} \max _{\mathrm{W}}-g_{\mathrm{W}}^{\text {cut }}\right) \\
& \times f_{\mathrm{Q}}(Q) \times f_{\mathrm{T}_{\mathrm{a}}}\left(T_{\mathrm{a}}\right) \times f_{\mathrm{D}}(D) \times f_{\mathrm{Ts}}\left(T_{\mathrm{s}}\right) \times f_{\mathrm{w}}\left(W_{\mathrm{s}}\right),
\end{aligned}
$$

where $\max _{\mathrm{SW}}$ is maximum, and $g_{\mathrm{W}}^{\text {cut }}$ is cuticular conductance for $\mathrm{H}_{2} \mathrm{O}, \mathrm{mmol} \mathrm{m} \mathrm{m}^{-2} \mathrm{~s}^{-1}$; $D$ is vapor pressure deficit in the air, $\mathrm{hPa} ; W_{\mathrm{s}}, \mathrm{mm}$, is available soil moisture supply, reckoned from wilting point. The values of all response functions $f_{\Phi}(\Phi)$ ( $\Phi$ is an ecological factor) lie in the range $[0,1]$. Simplest forms of $f_{\Phi}(\Phi)$ were selected. Usually applied hyperbola for radiation had the form $\left(Q_{05}, \mu \mathrm{mol} \mathrm{m} \mathrm{s}^{-1}\right.$, is a parameter)

$$
f_{Q}(Q)=Q\left(Q_{05}+Q\right)^{-1} \text {. }
$$

The temperature dependencies on $T_{\mathrm{a}}$ is taken as the quadratic parabola

$$
f_{\mathrm{Ta}}\left(T_{\mathrm{a}}\right)=\left\{\begin{array}{cl}
1-\left[\left(T_{\mathrm{aopt}, \mathrm{g}}-T_{\mathrm{a}}\right) /\left(T_{\mathrm{aopt}, \mathrm{g}}-T_{\text {amin, } \mathrm{g}}\right)\right]^{2}, & \text { when } T_{\text {amin }, \mathrm{g}} \leq T_{\mathrm{a}} \leq T_{\mathrm{amax}, \mathrm{g}}, \text { and } \\
0 & \text { otherwise. }
\end{array}\right.
$$


that has two parameters, $T_{\text {aopt, } g}$ and $T_{\text {amin, } g} ; T_{\text {amax }}$ $\mathrm{g}=2 T_{\text {aopt, }}-T_{\text {amin, } g}$. The function of the same form, $f_{\mathrm{Ts}}\left(T_{\mathrm{s}}\right)$, was introduced for the dependence on soil temperature; also, it was used as a multiplier to three key parameters of the biochemical model, $V_{\mathrm{cmax} 25}, J_{\max 25}$, and $\varphi$ (all they parameters - $T_{\text {opt, } g}$ and $T_{\text {min, }} \mathrm{g}$ were taken identical).

The dependence on vapor pressure deficit in the air was taken in hyperbolic form $\left(D_{00}\right.$ and $D_{05}$ are parameters, $\mathrm{hPa}$ )

$$
f_{\mathrm{D}}(D)=\left\{\begin{array}{cc}
1, & \text { when } D<D_{00}, \text { and } \\
{\left[1+\left(D-D_{00}\right) /\left(D_{05}-D_{00}\right)\right]^{-1}} & \text { otherwise }
\end{array}\right.
$$

The dependence on $W_{\mathrm{s}}$ was taken in the form of piece-wise linear function

$$
f_{\mathrm{W}}\left(W_{\mathrm{s}}\right)= \begin{cases}W_{\mathrm{s}} / W_{\mathrm{smax}}, \text { when } 0 \leq W_{\mathrm{s}}<W_{\text {smax }}, \text { and } \\ 1 & \text { otherwise }\end{cases}
$$

and has one parameter $W_{\text {smax }}, \mathrm{mm}$, the moisture level at which the stomata are at their maximum opening.

The photosynthesis and stomatal conductance submodels were combined on the basis of Fick's law of conductance and were solved together to get two unknowns - $A_{\mathrm{n}}$ and $C_{\mathrm{i}}$.

\subsubsection{Parametrizing the model}

The parameters for each species were estimated by the least squares method that minimises the residual sum of squared deviations (or standard error of estimate, SEE) between simulated and measured values of photosynthesis rate. Minimum SEE provides maximum of NashSutcliffe model efficiency criteria (ME) [28] that was used in our work; $M E=1$ corresponds to perfect fit while $M E<0$ says about inadequacy of a model.

Most model parameters considered secondary for the model performance were taken from the literature with their typical values. Temperature dependencies for $V_{\text {cmax } 25}, J_{\max 25}$, and $\mathrm{Ko}, \mathrm{Kc}$ (Michaelis constants for $\mathrm{CO}_{2}$ and $\mathrm{O}_{2}$ respectively) follow formulas used in [13], with their parameter values found as averages over several literature sources; quantum efficiency of photosynthesis $\varphi$ is taken as PHA and temperature-independent.
We had to abandon finding $V_{\text {cmax25 }}$ and $J_{\max 25}$ as independent parameters and instead fixed their ratio

$$
\Re=J_{\max 25} / V_{\text {cmax } 25}=2.25
$$

because of unrealistic values given by iterations, and fitted only one of them. This approach is repeatedly used in the literature [27,29,30]. A "reasonably-representative" value of $\Re=2.25$ was chosen, based on a review of published data on the coniferous species in the temperate zone $[11,12,13,15,31]$. The values of $R_{\mathrm{d} 25}$ were inferred from the plots of light curves for small values of $Q<80 \mu \mathrm{mol} \mathrm{m} \mathrm{m}^{-1} \mathrm{~s}^{-1}$. The parameters $T_{\text {amin, } g}$ and $T_{\text {smin, } g}$ were fixed for all species, $T_{\text {amin, }}$ $\mathrm{g}=T_{\text {smin, } \mathrm{g}}=-5^{\circ} \mathrm{C}$, with a negligible loss in accuracy. Parameters of the response functions in stomatal conductance, $Q_{05}, T_{\text {aopt, g }}, T_{\text {sopt, g }}, D_{00}$, $D_{0}, \quad W_{\text {smax }}$, were among those fitted by $S E E$ minimisation.

As a result, we had the set of 9 free parameters. Among them, $V_{\text {cmax } 25}, \varphi_{\text {opt }}$, and $\max _{\mathrm{SW}}$ were fitted by means of direct iterations, yielding a high degree of accuracy, with the other parameters remaining fixed; for them, we performed a grid search with a fixed parameter increment, and the cycle was repeated until a stable SEE minimum value was achieved.

\section{RESULTS}

\subsection{Differences in Species Reaction to Factors}

Fitting the model on the basis of the entire data set (1995-1999) gave the parameter values presented in Table 1.

The values of the optimal parameters listed in Table 1. The results clearly indicate inter-species differences and confirm the conclusions drawn from a preliminary examination of the experimental data:

a. The values of $V_{\mathrm{cmax} 25}$ and $\varphi_{\mathrm{opt}}$ show that the photosynthesis rate in larch is markedly lower compared with spruce and pine, whereas the last two species do not differ so much; accordingly, the values of $A_{\text {max }}$ differ;

b. The values of $Q_{05}$ are suggestive of a difference in the response of stomata to light (arrangement according to the sensitivity level: spruce, larch, pine); 
c. The values of $D_{00}$ and $D_{05}$ are indicative of a difference in the response of stomata to air moisture deficit (arrangement according to the sensitivity level: larch, spruce, pine);

d. The values of $W_{\text {smax }}$ indicate a difference in the response of stomata to soil moisture deficit (arrangement according to sensitivity level: pine, spruce, larch, with the first two species being virtually identical and sensitive, whereas larch is only weakly sensitive);

e. The values of $T_{\text {sopt }}$ point to a difference in the preferences of stomata and of the photosynthesis rate to soil temperature.

Table 1. Model parameter values obtaned by fitting the model using the entire data set for 1995-1999, together with some derivative variables. SEE is the standard error of estimate, ME is the model efficiency, $N$ is the number of data points

\begin{tabular}{|c|c|c|c|}
\hline Parameter and units & Larch & Spruce & Pine \\
\hline$V_{\text {cmax } 25}, \mu \mathrm{mol} \mathrm{m}{ }^{-2} \mathrm{~s}^{-1}$ & 25.6 & 54.5 & 74.0 \\
\hline$\varphi_{\mathrm{opt}}, \mathrm{mole}^{-}(\mathrm{mol} \text { PAR })^{-1}$ & 0.0604 & 0.0925 & 0.1223 \\
\hline$R_{\mathrm{d} 25}, \mu \mathrm{mol} \mathrm{m}{ }^{-2} \mathrm{~s}^{-1}$ & 0.611 & 1.937 & 1.576 \\
\hline$g_{\mathrm{SW}}^{\max }, \mathrm{mmol} \mathrm{m}^{-2} \mathrm{~s}^{-1}$ & 65.2 & 59.8 & 79.2 \\
\hline$T_{\text {aopt, },},{ }^{\circ} \mathrm{C}^{*}$ & 24.2 & 21.4 & 18.2 \\
\hline$T_{\text {sopt }, \mathrm{g}},{ }^{\circ} \mathrm{C}$ & 15.7 & 10.6 & 13.4 \\
\hline$Q_{05}, \mu \mathrm{mol} \mathrm{m}-2 \mathrm{~s}^{-1}$ & 90 & 30 & 150 \\
\hline$D_{00}, \mathrm{hPa}$ & 0.3 & 5.0 & 8.2 \\
\hline$D_{05}, \mathrm{hPa}$ & 8.0 & 13.6 & 22.0 \\
\hline$W_{\text {smax }}, \mathrm{mm}$ & 56 & 181 & 132 \\
\hline$A_{\max }, \mu \mathrm{mol} \mathrm{m}-2 \mathrm{~s}^{-1}$ & 3.26 & 4.61 & 6.07 \\
\hline$S E E, \mu \mathrm{mol} \mathrm{m}{ }^{-2} \mathrm{~s}^{-1}$ & 1.057 & 1.191 & 1.277 \\
\hline$M E$ & 0.493 & 0.458 & 0.656 \\
\hline$N$ & 4410 & 5730 & 5665 \\
\hline
\end{tabular}

Table 2. Quarter and yearly averages of ecological factors used (for symbols see the text)

\begin{tabular}{|c|c|c|c|c|c|c|}
\hline Years & $\begin{array}{l}Q, \mathrm{~mol} \mathrm{~m}^{-2} \\
\text { day }^{-1}\end{array}$ & $T_{\mathrm{a}},{ }^{\circ} \mathrm{C}$ & $\begin{array}{l}D, \\
\mathrm{hPa}\end{array}$ & $T_{s},{ }^{\circ} \mathrm{C}$ & $W_{\mathrm{s} 50}, \mathrm{~mm}$ & $\begin{array}{l}\text { Precipitation, } \\
\text { mm month }^{-1}\end{array}$ \\
\hline 1995 I & 45.6 & 14.8 & 7.9 & 11.7 & 111.9 & 31 \\
\hline II & 45.1 & 20.7 & 9.5 & 18.0 & 45.8 & 83 \\
\hline III & 25.0 & 10.1 & 3.0 & 11.0 & 71.0 & 28 \\
\hline Average & 38.6 & 15.2 & 6.8 & 13.6 & 76.2 & 47 \\
\hline 1996 I & 38.8 & 17.9 & 9.7 & 12.8 & 86.2 & 9 \\
\hline II & 43.6 & 20.5 & 7.9 & 17.5 & 74.3 & 118 \\
\hline III & 25.4 & 9.6 & 5.0 & 9.8 & 48.3 & 20 \\
\hline Average & 35.9 & 16.0 & 5.9 & 13.4 & 69.6 & 49 \\
\hline 1997 I & 44.7 & 14.4 & 8.6 & 7.5 & 106.6 & 25 \\
\hline II & 42.7 & 21.2 & 7.7 & 16.6 & 41.6 & 110 \\
\hline III & 20.1 & 10.5 & 3.2 & 9.1 & 41.0 & 32 \\
\hline Average & 35.8 & 15.4 & 6.5 & 10.0 & 63.0 & 56 \\
\hline 19981 & 39.6 & 11.7 & 8.8 & 5.3 & 62.7 & 26 \\
\hline II & 44.7 & 24.9 & 10.2 & 18.5 & 77.9 & 122 \\
\hline III & 15.9 & 6.0 & 2.3 & 6.5 & 42.7 & 35 \\
\hline Average & 33.4 & 14.2 & 7.1 & 10.1 & 61.1 & 61 \\
\hline 1999 I & 44.6 & 15.3 & 11.4 & 8.2 & 64.4 & 22 \\
\hline II & 42.6 & 20.9 & 8.0 & 16.2 & 44.3 & 82 \\
\hline III & 21.3 & 8.5 & 4.6 & 7.1 & 29.9 & 13 \\
\hline Average & 36.2 & 14.9 & 8.0 & 10.5 & 46.2 & 39 \\
\hline 1995-99 & 36.0 & 15.1 & 6.9 & 11.5 & 63.2 & 50 \\
\hline
\end{tabular}


General quality of model perfomance is supported by the values of ${ }_{g_{\mathrm{SW}}}$ ax that lie within the range usually reported for coniferous trees, as well as a good correspondence between the observed and theoretical values of $T_{\text {aopt }}$. Also, the observed interrelation between temperature optima for stomata operating, $T_{\text {aopt, } g}>T_{\text {sopt, } g}$, corresponds to the observed interrelations for $T_{\mathrm{a}}$ and $T_{\mathrm{s}}$ (Table 2).

\subsection{Stomatal Conductance Limitatioins}

The limitation of photosynthesis by stomatal conductance was estimated by the parameter $L_{s}$ suggested by Sharkey (unpublished, cited from [32]: we took the actual rate of photosynthesis found from equation (1), $A_{\mathrm{n}}\left(C_{\mathrm{i}}\right)$, and then used the same equation to calculate the maximal rate of photosynthesis, $A_{n}\left(C_{\mathrm{a}}\right)$, with the intracellular concentration of $\mathrm{CO}_{2}$ equal to the ambient one, $C_{\mathrm{i}}=C_{\mathrm{a}}$, that is provided by formally infinite stomatal conductance. After that the value of $L_{s}$ can be found as

$$
L_{\mathrm{s}}=\left(A_{\mathrm{Ca}}-A_{\mathrm{Ci}}\right) / A_{\mathrm{Ca}},
$$

that gives the relative value of stomatal limitation $\left(L_{s}=0\right.$ corresponds to no limitation, while $L_{s}=1$ corresponds to the maximal one). It was found that during an actual weather period, $L_{\mathrm{s}}=0.30 \mathrm{in}$ larch, and 0.46 and 0.49 in spruce and pine, respectively. Value of $L_{s}$ considerably varied between years of observation, e.g., in the dry 1999 season it increased to 0.59 and 0.64 for spruce and pine, respectively.

To determine the influence of the external factors on $L_{\mathrm{s}}$ separately, a calculation was performed for the case where one of the factors $\Phi=\left(Q, T_{\mathrm{a}}, D\right.$, $\left.T_{\mathrm{s}}, W_{\mathrm{s}}\right)$ was at its optimum. As is evident from Fig. 1, stomatal regulation is minimal in larch and maximal in pine. At the optimal $W_{s}$, the value of $L_{s}$ in spruce and pine decreased. In larch, it decreased dramatically when $D=0$, and under constantly clear weather it increased in all species.

\subsection{Analysis of Long-term Acclimations}

Determination of model parameters on the entire data set implies that all the parameters stay constant during the whole observation period. At the same time, general biological considerations as well as observational data support the view that the parameters are not constant but can vary under ecological factor change. In our case, the weather changed noticeably between the years as well as from quarter to quarter within a year. Hence, one can suggest that species parameters will change correspondingly.

It is worth noting that for all factors besides $W_{\mathrm{s}}$ the seasonal dynamics for every year was similar: values of $Q, D, T_{\mathrm{a}}$, and $T_{\mathrm{s}}$ reached their maxima in the middle of the summer. On the contrary, the value of $W_{\mathrm{s}}$ could be maximal either in spring, summer or in autumn; year 1999 was dry. Table 2 presents between-quarter variability of ecological factors applied in the model.

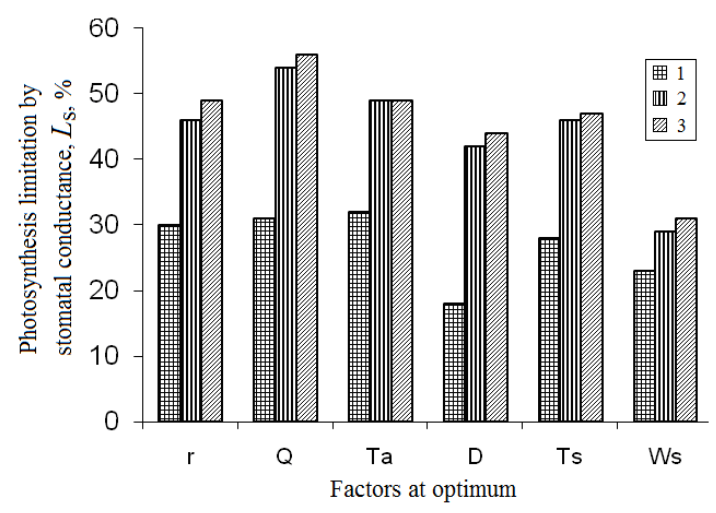

Fig. 1. Proportion of photosynthesis limitation by stomatal conductance, $L_{s}$, \%, formula (9), for different weather scenarios according to the data from 1995-1999

$r$-actual weather;

$Q$ - sunny weather, the other factors are from the actual weather;

$T_{a}$ and $T_{s}$-optimal air or soil temperature, the other factors are from the actual weather;

$W_{s}$ - optimal soil moistening, the other factors are from the actual weather;

$D=0$, the other factors are from the actual weather. 1 - larch, 2 - spruce, 3 - pine

In order to examine the hypothesis concerning long-term parameter change, we fitted the model to three data sets arranged by specific time periods:

A) The entire data set for 1995-1999 (see the results in Table 1).

B) Each year treated separately. Because of the smaller number of points and the considerable data scatter, only three key parameters - $V_{\text {cmax25 }}\left(J_{\max 25}\right), \varphi_{\text {opt }}$, and $g_{\mathrm{sw}}$ taken as common (from the entire data set fitting for 1995-1999, Table 1). The results are presented in Table 3. 
C) Each quarter treated separately (April mid-June (spring), mid-June - August (summer), and September - October (fall), designated as I, II, and III); again, only three parameters $V_{\text {cmax } 25}, \varphi_{\text {opt }}$, and ${ }_{g_{\mathrm{SW}}}$ were fitted.

The results from calculations according to the years (Table 3 ) show that the values of $V_{\text {cmax25 }}$ $\left(J_{\max 25}\right)$ and $A_{\max }$ can differ by as much as a factor of three.

In parametrizing the model for the quarters (the results are not reported here) it was found that the parameter values vary markedly but irregularly with seasons. For example, the ranges of variation of $V_{\mathrm{cmax} 25}$ were: 9-51 for larch, 13120 for spruce, and 41-174 $\mathrm{mmol} \mathrm{m}^{-2} \mathrm{~s}^{-1}$ for pine. The resulting variations are most likely associated with weather changes; in most cases, however, it was not possible to reveal a reliable correlation with separate environmental factors. The value of $A_{\max }$ varied during different years and during a season together with the value of $V_{c m a x 25}$, and the variations were well correlated with one another, yielding $M E=0.73$ (Fig. 2).

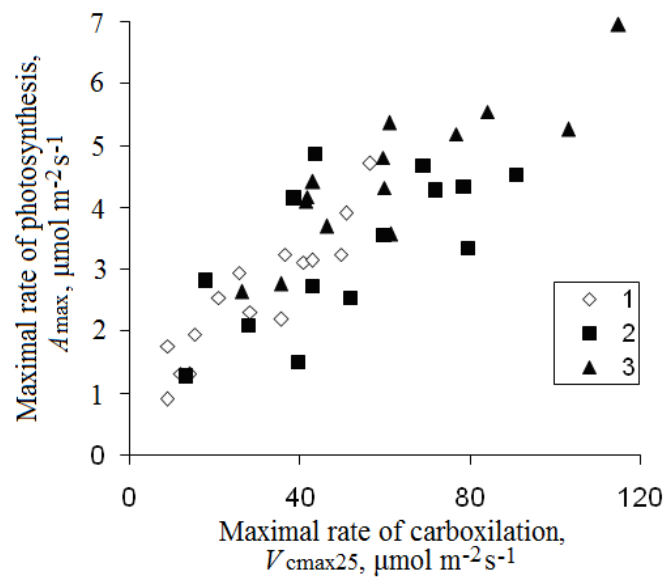

Fig. 2. $V_{\text {cmax } 25}$ vs. $A_{\max }, 15$ season measurements per species. 1 - larch, 2 spruce, 3 - pine

The resulting three sets of optimal parameters allowed us to estimate the influence of the variation of the parameter values for the years and for the quarters of a given year. To do this, we can use the analogue of "piecewise interpolation" and calculate the value of $M E$ when $A_{\text {theor }}$ values are calculated from the parameters found for each year and for each quarter. The extent to which $M E$ increased with such a decrease of the fitting intervals will show how substantial the parameter variation over time is. As is evident (Table 4), the description quality is improved markedly when one goes over from the entire set to the by-year set, but improved only slightly with further fragmentation into quarters.

The mean values of $A_{\text {theor }}$ for a quarter, calculated from the parameter for each year, virtually coincide with the values of $A_{\text {empir }}$ (Fig. 3), while for the parameters obtained for the entire data set, the agreement is much worse. This is especially clear for spruce and larch, whereas the photosynthesis rates $A_{\text {theor }}$ for pine are in good agreement with $A_{\text {empir }}$ being obtained by any method of parameter calculation.

The foregoing discussion leads to the conclusion that to calculate $A_{\text {theor }}$ it is appropriate to use the parameters obtained from the data either for separate years or (if the number of observations is sufficiently large) for quarters of a year; using several years data together seriously decreases the accuracy of fitting. Also, it should be borne in mind that a decrease in the number of observation points enhances the likelihood of obtaining unrealistic parameter values (the system becomes "informationally unstable").

\subsection{Examination of Optimal Photo- synthesis Rate}

As soon as one has the tool to simulate the dependence of photosynthesis rate on five external factors, a numerical experiment can be carried out to calculate what the rate of net photosynthesis would be if all the external conditions were optimal. Let us operate with the photosynthesis rates found as the averages over the whole observation period, and denote the optimal rate as $A_{\max }$. If the $A_{\text {act }}$ is the rate of photosynthesis at actual weather, then ratio $A_{\text {act }} /$ $A_{\max }$ gives the measure of realization of the capabilities of the photosynthetic apparatus under actual habitat conditions.

According to Table 5, larch, spruce and pine at actual weather realize, on average, $49 \%, 30 \%$, and $36 \%$ of their respective potential. Table 5 also provides information as to how photosynthesis would increase, if only one of the factors $\Phi=\left(Q, T_{\mathrm{a}}, D, T_{\mathrm{s}}, W_{\mathrm{s}}\right)$ was at its optimum; a photosynthesis rate increment was found as

$$
\Delta_{\Phi \mathrm{k}}=100\left(A_{\Phi \mathrm{kopt}}-A_{\mathrm{act}}\right) / A_{\mathrm{act}}
$$


where $\Phi_{\mathrm{k}}$ is factor $k, A_{\Phi \mathrm{k} \text { opt }}$ is the mean partially optimal photosynthesis (the factor $\Phi_{k}$ is in optimum, while the others correspond to actual weather). This quantity is, essentially, the measure of limitation of photosynthesis by each of the factors in a given climate. Negative value of $\Delta_{\Phi k}$ for spruce seem to be due to the dependence $T_{\text {a opt, A theor }}(Q)$.
As is evident from Table 5, the greatest influence on the rate of photosynthesis is exerted by vapor pressure deficit for larch, and by soil moisture content for spruce and pine. The priority influence of these factors on photosynthesis is observed for all years used in the study, although the value fluctuates from year to year.

Table 3. The result from fitting the model parameters $\left(V_{\mathrm{cmax} 25,}, \varphi_{\mathrm{opt}},{ }^{g_{\mathrm{sw}}}\right)$ using the data for each year. See Table 1 for the denotations

\begin{tabular}{|c|c|c|c|c|c|c|}
\hline Years & $\begin{array}{l}V_{\text {cmax } 25,} \\
\mu \mathrm{mol} \mathrm{m}{ }^{-2} \mathrm{~s}^{-1} \\
\end{array}$ & $\begin{array}{l}\varphi_{\text {opt }}, \mathrm{mol} \mathrm{e}^{-} \\
(\mathrm{mol} \text { PAR })^{-1}\end{array}$ & 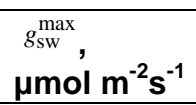 & SEE & $M E$ & $N$ \\
\hline \multicolumn{7}{|l|}{ Larch } \\
\hline 1995 & 15.2 & 0.0353 & 93.1 & 0.72 & 0.72 & 975 \\
\hline 1996 & 31.8 & 0.0631 & 59.6 & 0.86 & 0.69 & 810 \\
\hline 1997 & 42.9 & 0.0907 & 67.1 & 1.19 & 0.55 & 870 \\
\hline 1998 & 29.8 & 0.0655 & 104.4 & 0.85 & 0.70 & 915 \\
\hline 1999 & 9.6 & 0.0225 & 222.7 & 0.73 & 0.33 & 840 \\
\hline \multicolumn{7}{|c|}{ Spruce } \\
\hline 1995 & 29.4 & 0.0810 & 39.3 & 1.20 & 0.34 & 1110 \\
\hline 1996 & 44.8 & 0.0911 & 117.7 & 1.16 & 0.63 & 975 \\
\hline 1997 & 53.3 & 0.1031 & 81.0 & 1.12 & 0.61 & 1140 \\
\hline 1998 & 120 & 0.0903 & 68.0 & 0.98 & 0.56 & 1335 \\
\hline 1999 & 43.1 & 0.1170 & 25.8 & 0.67 & 0.35 & 1170 \\
\hline \multicolumn{7}{|l|}{ Pine } \\
\hline 1995 & 39.9 & 0.1088 & 141.7 & 1.31 & 0.74 & 1170 \\
\hline 1996 & 37.1 & 0.0846 & 154.3 & 1.27 & 0.69 & 974 \\
\hline 1997 & 75.9 & 0.1618 & 94.0 & 1.44 & 0.65 & 1061 \\
\hline 1998 & 130 & 0.1274 & 65.0 & 1.06 & 0.62 & 1290 \\
\hline 1999 & 75.7 & 0.1255 & 52.3 & 0.88 & 0.56 & 1170 \\
\hline
\end{tabular}

Table 4. Model efficiency, ME found for three optimal parameter sets

\begin{tabular}{llll}
\hline Method to calculate the parameters & Larch & Spruce & Pine \\
\hline Total data set (Table 1) & 0.493 & 0.458 & 0.656 \\
For years & 0.646 & 0.588 & 0.697 \\
For quarters & 0.676 & 0.610 & 0.721 \\
Number of points & 4410 & 5730 & 5665 \\
\hline
\end{tabular}

Table 5. The increase in average (for the 1995-1999 period) photosynthesis rate for different weather scenarios. $A_{\text {act }}$ and $A_{\max }$ are the values under actual and optimal weather, in $\mu \mathrm{mol} \mathrm{m}$ $\mathbf{s}^{-1} . \Delta_{\Phi \mathrm{k}}$ is relative photosynthesis rate increment given by formula (11)

\begin{tabular}{|c|c|c|c|c|c|c|c|}
\hline \multirow[t]{2}{*}{$A_{\text {act }}$} & \multirow[t]{2}{*}{$A_{\max }$} & \multirow{2}{*}{$\underset{\%}{\boldsymbol{A}_{\text {act }} / \boldsymbol{A}_{\max },}$} & \multicolumn{5}{|c|}{$\Delta_{\Phi}$ at a factor $\Phi$ in optimum } \\
\hline & & & $Q$ & $T_{\mathrm{a}}$ & $D$ & $T_{\mathrm{s}}$ & $W \mathbf{s}$ \\
\hline \multicolumn{8}{|l|}{ Larch } \\
\hline $\begin{array}{l}1.58 \\
\text { Spruce }\end{array}$ & 3.26 & 48.5 & 6.1 & 12.0 & 31.1 & 4.8 & 5.9 \\
\hline 1.37 & 4.61 & 29.6 & 11.1 & -1.8 & 25.0 & 5.6 & 78.2 \\
\hline \multicolumn{8}{|l|}{ Pine } \\
\hline 2.17 & 6.07 & 35.7 & 15.5 & 4.1 & 13.9 & 9.5 & 63.7 \\
\hline
\end{tabular}




\section{DISCUSSION}

From a technical point of view, our approach to parameter fitting differs from that accepted in the literature where parameters $V_{\text {cmax25 }}$ and $J_{\max 25}$ are found from $A-C_{i}$ curves treatment while the others are fitted to photosynthesis rate data. We found all the parameters of the combined model by means of direct fitting to measurement data. In general, our results are in a good agreement with those reported in the literature $[33,34,35]$ and many others.
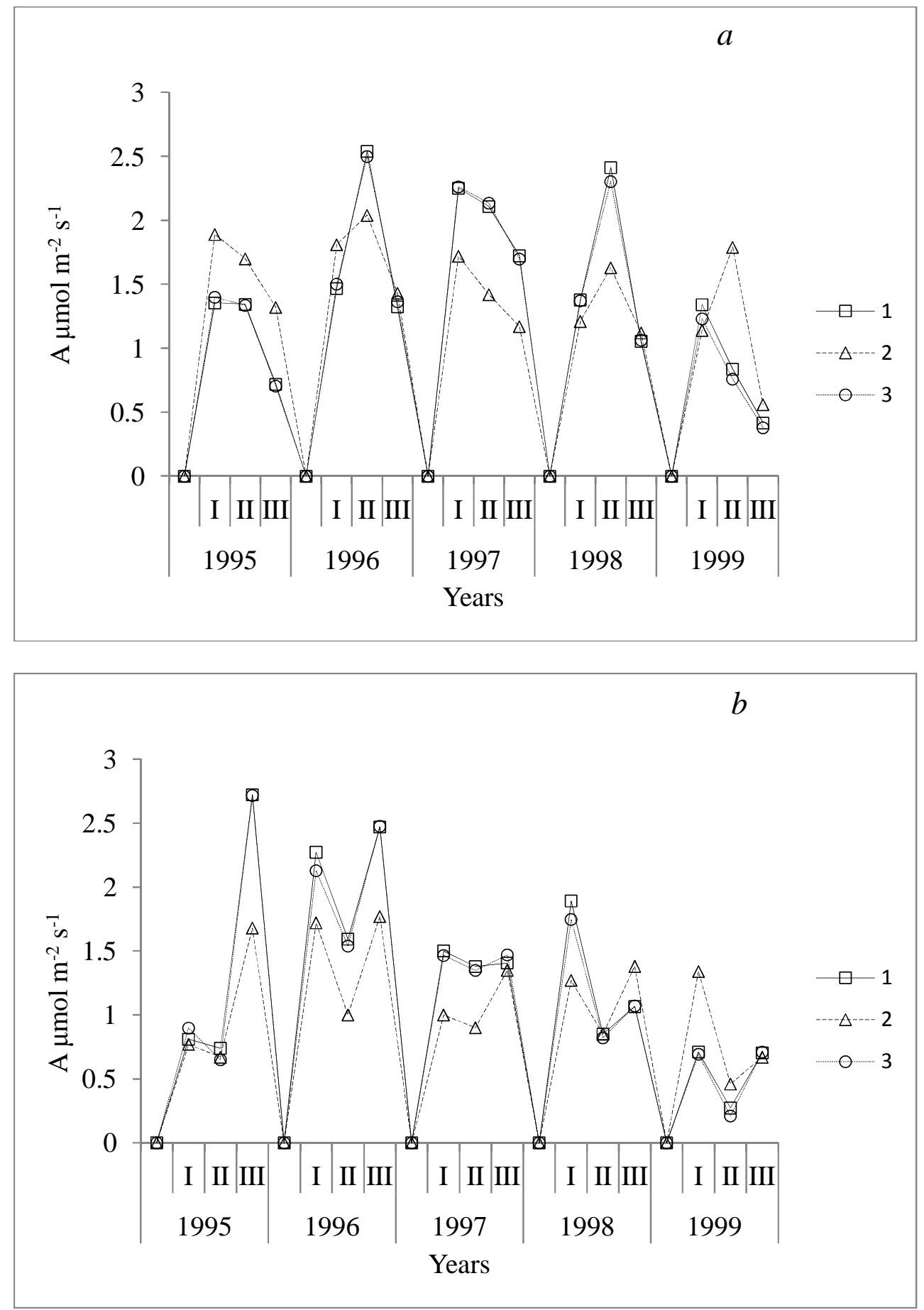


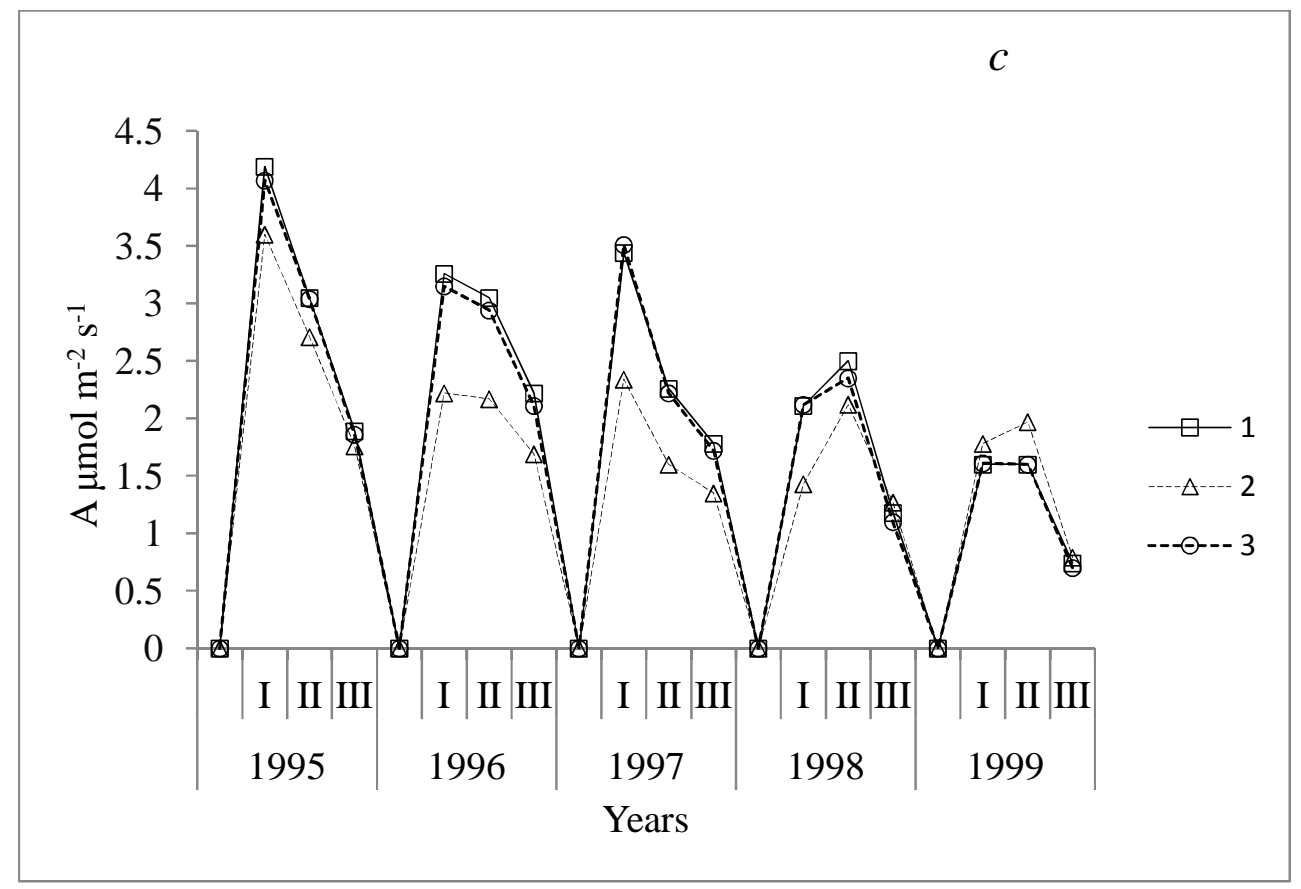

Fig. 3. Dynamics of net photosynthesis rate (quarterly averaged data): 1 - data of measurement; 2,3 - predicted values: 2 - from the parameters obtained from the entire data set. 3 - from the parameters obtained from the data for each year individually. $a$ - larch, $b-$ spruce, $c$ - pine

The analysis of long-term $\mathrm{CO}_{2}$ exchange measurements made in this study using the mathematical model showed that the three species under investigation clearly differ in their physiological characteristics: in the mean rate of photosynthesis, in the sensitivity to the effect of ambient conditions, as well as in the degree of photosynthesis limitation by stomatal conductance.

Larch is known to be a light-demanding, rapidly growing species with a high rate of photosynthesis. The data available in the literature refered to photosynthesis for other of larch species and for Larix sibirica obtained by [36] and calculated on the basis of neadle dry matter, confirm this opinion: its entire daily photosynthesis is 2-3 times higher than that of pine and 4-5 times higher than of spruce (but the same rate of photosynthesis in larch calculated on $1 \mathrm{~m}^{2}$ needle surface basis appeared unexpectedly low). Sensitivity of stomata to variations in $D$, and low sensitivity to $W_{\mathrm{s}}$ corresponds to larch ability for rapid regeneration of its photosynthetic activity after high wind and growing air moisture with no changes in $W_{\mathrm{s}}$ [37]. For spruce, sensitivity of stomata to changes in $Q$ corresponds well to observations [36].
For pine, the widest range of Rubisco activity found in calculations $\left(V_{\mathrm{cmax} 25}=41-174 \mu \mathrm{mol} \mathrm{m} \mathrm{m}^{-2}\right.$ $\mathrm{s}^{-1}$ ) corresponds well to our earlier guess [19] about presence of three Rubisco isomorphes in its needles to support a stable photosynthetic activity during the season of vegetation.

The analysis conducted on the parameter values fitted to the whole data set allows one to examine the photosynthesis rate dependence only on the ecological factor values at the time of measurement. But long-term factor change usually results in plant state variation, that is, in plant parameter change. Literature data says that Farquhar model parameters are not constant within even given species. For example, it was shown that $V_{\text {cmax25 }}$ and $J_{\max 25}$ can differ markedly over the course of a vegetation season $[12,27,38]$ depending on leaf and tree age $[39,40,31]$ or along vertical canopy profile $[30,38,41]$.

We are aware of few studies e.g., $[12,17]$ where $V_{\text {cmax25 }}$ value was correlated with weather conditions. The necessary duration of external influence has scarcely been studied. Some previous data [16] indicate that when plants are transferred from shade to an open place and 
back - from light to shadow, the rearrangement of the light curves of photosynthesis, which is also accompanied by changes of the size and number of chloroplasts, occurs over two weeks following the change in the light regime.

As we found, variations in the parameter values between seasons can lead to a considerable change in the rate of photosynthesis. In this context, it can be said that when estimating the degree of influence of external factors on photosynthesis without taking into account the changes of the model parameters, we underestimate this influence. It seems likely that the change in the photosynthesis parameter values could be understood as a plants' acclimation to environmental conditions.

Time variation of the model parameters limits considerably the predictive value of the generally accepted Farquhar model. The question concerning the reasons for Farquhar model parameter variations needs further examination. Nevertheles, we suggest that the parameter differencies revealed, actually reflect evolutionally formed differencies in photosynthesis features of the species.

Calculation of the optimal photosynthesis allowed us to estimate at what degree a species realizes its production potential. As was revealed from a comparison of actual, $A_{\text {act }}$, and maximal photosynthesis, $A_{\text {act }}$ constitutes $49 \%$ for larch, $30 \%$ for spruce, and $36 \%$ for pine of $A_{\max }$. This can be interpreted to mean that spruce under this climate realizes its photosynthetic potential less effectively when compared with the other two species. This is consistent with forestry evidence that spruce is less distributed in this region - only $7 \%$ compared with $34 \%$ and $40 \%$ of pine and larch stands. The fact that photosynthesis in spruce responds more strongly to available moisture content in the soil than photosynthesis in larch does is also in agreement with forestry data: spruce stands occupy mainly small river valleys [3], whereas larch occupies all the habitats [21]. On the other hand, the strong response of photosynthesis in pine to the value of $W_{\mathrm{s}}$ is in disagreement with the fact that pine usually grows over a wide range of soil moistering conditions.

\section{CONCLUSION}

Our results from processing the five-year-long photosynthesis observations in three coniferous species in the Pre-Baikalia - larch, spruce, and pine, allowed us to refine the technique for developing and analyzing the combined Farquhar and stomatal conductance model using the available data. It was shown that more reliable parameter values are obtained using the data for individual years and for individual quarters.

Among the species under investigation, pine has the highest rate of photosynthesis. As far as spruce and larch are concerned, the rate of photosynthesis is far lower. The considerable fluctuations of the rate of photosynthesis from year to year as well as from season to season are associated with the effect of ambient conditions at the time of photosynthesis measurements as well as (perhaps even to a greater extent) with the rearrangement of the photosynthetic apparatus due to long-term influence of external conditions of varying intensity. Whereas the values of $A_{\max }$ vary from year to year over a wide range as a result of the changes of the model parameter values, the relationship between actual and optimal photosynthesis does not change as strongly from year to year.

Limitation of photosynthesis through stomatal conductance affects pine most of the three, and larch least of them.

The numerical experiment allowed us to estimate the extent to which different climatic factors influence the limitation of photosynthesis in different coniferous species. It was found that under actual weather conditions of the PreBaikalia the species under investigation realize $49 \%$ (larch), 30\% (spruce), and 36\% (pine) of their photosynthetic potential. The greatest influence on photosynthesis is exerted by vapor pressure deficit for larch, and by the soil moisture content for spruce and pine.

\section{COMPETING INTERESTS}

Authors have declared that no competing interests exist.

\section{REFERENCES}

1. Shimanyuk AP. Pine forests in Siberia and the Far East. Moscow, Russia; 1962.

2. Popov LV. South-taiga forests of Central Siberia. Irkutsk: Izdat. Gos. Univ., Russia; 1982. 
3. Vashchyuk LN, Popov LV, Krasnyi NM. Forests and forestry of the Irkutsk region. Ed.: L.N. Vashchyuk. Irkutsk, Russia; 1997.

4. Farquhar GD, von Cammerer S, Berry JA. A biochemical model of photosynthetic $\mathrm{CO}_{2}$ assimilation in leaves of $\mathrm{C} 3$ species. Planta. 1980;149:78-90.

5. El-Masri B, Barman R, Meiyappan P, Song $\mathrm{Y}$, Liang $\mathrm{M}$, Jain AK. Carbon dynamics in the amazonian basin: Integration of eddy covariance and ecophysiological data with a land surface model. Agric For Meteorol. 2013;19:1759-1779.

6. Verheijen LM, Brovkin V, Aerts R, Bönisch G, Cornelissen JHC, Kattge J, Reich PB, Wright IJ, van Bodegom PM. Impacts of trait variation through observed traitclimate relationships on performance of an Earth system model: A conceptual analysis. Biogeosciences. 2013;10:54975515.

7. Barman R, Jain AK, Liang M. Climatedriven uncertainties in modeling terrestrial gross primary production: A site level to global-scale analysis. Global Change Biology. 2014;20(5):1394-1411.

8. Medlyn BE, Zaehle S, De Kauwe MG, et al. (20 authors). Using ecosystem experiments to improve vegetation models. Nature Climate Change. 2015;5:528-534.

9. Jarvis PG. The interpretation of the variations in leaf water potential and stomatal conductance found in canopies in the field. Phil. Trans. Roy. Soc. London, Ser. B. 1976;273:693-610.

10. Ball JT, Woodrow E, Berry JA. A model predicting stomatal conductance and its contribution to the control of photosynthesis under different environmental conditions. In: Progress in Photosynthesis Research Ed J. Biggins M Nijhoff Publishers, Dordrecht. 1987;221224.

11. Wullschleger SD. Biochemical limitations to carbon assimilation in $\mathrm{C} 3$ plants. A retrospective analysis of $\mathrm{A} / \mathrm{Ci}$ curves from 109 species. J. Exp. Bot. 1993;44:907920.

12. Medlyn BE, Loustau D, Delson S. Temperature response of parameters of a biochemically based model of photosynthesis. I. Seasonal changes in mature maritime pine (Pinus pinaster Ait.). Plant Cell Environ. 2002a;25:1155-1165.

13. Medlyn BE, Dreyer E, Ellsworth D, Forstreuter M, Harley PC, Kirschbaum
MUF, Le Roux $X$, Montpied $P$, Strassemeyer Walcroft A, Wang $K$, Loustau D. Temperature response of parameters of a biochemically based model of photosynthesis. II. A review of experimental data. Plant Cell Environ. 2002b;9:1167-1179.

14. Dang QL, Cheng S. Effects of soil temperature on ecophysiological traits in boreal trees. For. Ecol. Manage. 2004;194: 379-387.

15. Cai T, Dang QL. Effects of soil temperature on parameters of a coupled photosynthesis- stomatal conductance model. Tree Physiol. 2002;22:819-828.

16. Tselniker YuL, Malkina IS, Knyazeva IF. Response of the photosynthetic apparatus of Bosnian maple to changes of the illumination regime. Plant Physiology (Fiziologiya Rasteniy) 1971;18:1127-1133.

17. Scheberg PG, Wilkinson RC, Shane JB, Donnelly JR, Cali PE. Winter photosynthesis of red spruce from three Vermont seed sources. Tree Physiol. 1995;15:345-350.

18. Bernacchi CJ, Bagley JE, Serbin SP, RuizVera UM, Rosenthal DM, Vanloocke A. Modelling C3 photosynthesis from the chloroplast to the ecosystem. Plant Cell and Environment. 2013;36(9):1641-1657.

19. Suvorova GG. The photosynthesis of coniferous trees in conditions of Siberia. Novosibirsk: Geo, SB. 2009;195

20. Koropachinsky IYu. Woody plants of Siberia. Novosibirsk: Nauka. SB; 1983.

21. Osawa A, Zyryanova OA, Matsuura Y, Kajimoto T, Wein RW. Permafrost ecosystems, Siberian larch forests. Ecological Studies. XXVI. Springer Science+Business Media. 2010;209:502.

22. Vashchuk LN, Shvidenko AZ. Dynamics of forest spaces of Irkutsk region. Irkutsk: O०O "Irkutskaja Oblastnaj Typografia N 1"; 2006.

23. Kolesnichenko VT. Influence of fertilizers on grain harvest and quality of winter Wheat "Zalarinka" in the Irkutsk Region (Results of Field Experiments). Moscow: OOO "NPK Prombezopasnost"; 2004.

24. Shcherbatyuk AS. Multi-channel devices with $\mathrm{CO} 2$ gas analyzers for laboratory and field research. In: Infra-red gas analyzers as used in the study of gaseous exchange of plants. Moscow: Nauka. 1990;38-54.

25. Larcher W. Physiological plant ecology. Third edition. Springer. Berlin. Heidelberg; 1995. 
26. Tselniker YuL, Korzukhin MD, Suvorova GG, Yankova LS, Kopytova LD, Filippova AK. In: Problems of ecological monitoring and ecological modeling. Ed.: Ju. A. Israel. Saint-Petersburg, Hydrometeoizdat Publishers. 2007;21:265-292.

27. Kosugi $\mathrm{Y}$, Shibata S, Kobashi S Parametrization of the $\mathrm{CO}_{2}$ and $\mathrm{H}_{2} \mathrm{O}$ gas exchange of several temperate deciduous broad-leaved trees at the leaf scale considering seasonal changes. Plant Cell Environ. 2003;26:285-301

28. Nash JE, Sutcliffe JV. River flow forecasting through conceptual models, Part I - A discussion of principles. Journal of Hydrology. 1970;10:282-290.

29. De Pury DGG, Farquhar GD. Simple scaling of photosynthesis from leaves to canopies without the errors of big-leaf errors. Plant Cell Environ. 1997;20:537557.

30. Baldocchi DD, Meyers T. On using ecophysiological, micrometeorological and biogeochemical theory to evaluate carbon dioxide, water vapor and trace gas fluxes over vegetation: A perspective. Agric for Meteorol. 1998;90:1-25.

31. Rayment MB, Loustau D, Jarvis PJ. Photosynthesis and respiration of black spruce at three organizational scales: Shoot, branch and canopy. Tree Physiol. 2002;22:219-229.

32. Farquhar GD, Sharkey TD. Stomatal conductance and photosynthesis. Annual Review of Plant Physiol. 1982;33:317-345.

33. Medlyn BE, Badeck FW, de Pury DGG, Barton CVM, Broadmeadow $M$, Ceulemans $\mathrm{R}$, De Angelis $\mathrm{P}$, Forstreuter $M$, Jach ME, Kellomäki S, Laitat E, Marek M, Philippot S, Rey A, Strassemeyer J, Laitenen K, Liozon R, Portier B, Roberntz $P$, Wang $K$, Jarvis PG. Effects of elevated [CO2] on photosynthesis in European forest species: A meta-analysis of model parameters. Plant, Cell and Environment. 1999;22:1475-1495.

34. Kucharik CJ, Foley JA, Delire C, Fisher VA, Coe MT, Lenters J.D, Young-Molling
C, Ramankutty N, Norman JM, Gower ST. Testing the performance of a dynamic global ecosystem model: Water balance, carbon balance, and vegetation structure. Global Biogeochemical Cycles. 2000; 14(3):795-825.

35. Bonan GB, Lawrence PJ, Oleson KW, Levis S, Jung M, Reichstein M, Lawrence DM, Swenson SC. Improving canopy processes in the community land model version 4 (CLM4) using global flux fields empirically inferred from FLUXNET data Journal of Geophysical Research: Biogeosciences G02014. 2011;116.

DOI: 10.1029/2010JG001593

36. Shcherbatyuk AS, Rusakova LV, Suvorova GG, Yankova LS. Carbon dioxide gas exchange of the Pre-Baikalia's conifers. Novosibirsk: Nauka, SB; 1991.

37. Suvorova GG. Photosynthesis and growth of coniferous species of the forest-steppe Pre-Baikalia: Abstract of Ph.D. (biology) dissertation. Irkutsk, Russia; 1992.

38. Wilson KB, Baldocchi DD, Hanson PJ. Quantifying stomatal and non-stomatal limitations to carbon assimilation resulting from leaf aging and drought in mature deciduous tree species. Tree Physiol. 2000;20:787-797.

39. Niimets Ü. Stomatal conductance alone does not explain the decline in foliar photosynthetic rates with increasing tree age and size in Picea abies and Pinus sylvestris. Tree Physiol. 2002;22:515-535.

40. Dungan RJ, Whitehead D, Dungan, RP. Seasonal and temperature dependence of photosynthesis and respiration for two cooccuring broad-leaved tree species with contrasting leaf phenology. Tree Physiol. 2003;23:561-568

41. Medrano H, Escalona JM, Bota J, Gulias J, Flexas J. Regulation of photosynthesis of C3 plants in response to progressive drought: Stomatal conductance as a reference parameter. Ann. Bot. 2002; 89:895-905.

(C) 2017 Suvorova et al.; This is an Open Access article distributed under the terms of the Creative Commons Attribution License (http://creativecommons.org/licenses/by/4.0), which permits unrestricted use, distribution, and reproduction in any medium, provided the original work is properly cited.

Peer-review history:

The peer review history for this paper can be accessed here: http://sciencedomain.org/review-history/18773 